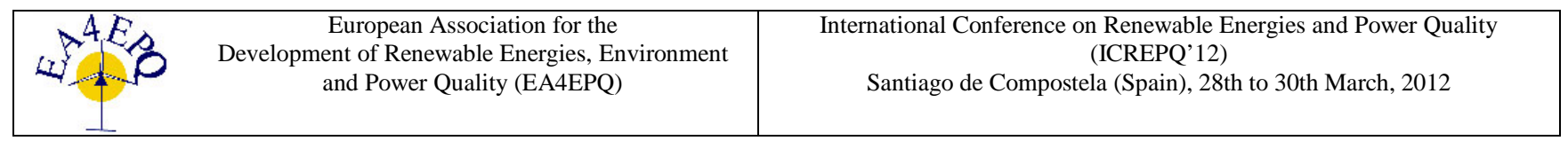

\title{
Optimal Allocation of Mega-solar Power Station using Integrated Input and Output-oriented models in Data Envelopment Analysis
}

\author{
S. Yokota ${ }^{1}$, T. Kumano ${ }^{2}$ \\ ${ }^{1}$ Graduate School of Science and Technology \\ Meiji University \\ 1-1-1, Higashi-mita Tama-ku, Kawasaki 214-8571(Japan) \\ Phone/Fax number:+81 0905100 5932, e-mail: ce11094@meiji.ac.jp \\ ${ }^{2}$ Professor, School of Science and Technology \\ Meiji University \\ Phone/Fax number:+81 44934 7294, e-mail: kumano@isc.meiji.ac.jp
}

\begin{abstract}
In this paper, optimal allocation of mega-solar power station is studied using Data Envelopment Analysis (DEA). In Japan, A great attention is paid to natural energy. Especially, installation of a mega-solar station, which is a large photovoltaic power plant over $1 \mathrm{MW}$, is beginning. In order to propose the optimal allocation, DEA method is applied in this research. Land cost, earthquake occurrence, transmission loss are used as inputs, and the amount of global solar radiation, and population density are used as outputs. The target locations are at 81 points in 5 prefectures of Chubu District in Japan. We perform ranking in consideration of input-oriented and output-oriented in BCC model, and successfully get solutions about the mega-solar optimal allocation.
\end{abstract}

\section{Key words}

Data Envelopment Analysis, Mega-solar, Sensitivity Analysis, Decision Making Unit, Linear Programming Problem

\section{Introduction}

A great earthquake occurred in the eastern Japan on March 11, 2011, and it fell into electric power shortages from the stop of the Fukushima nuclear power plant, etc. People have become intensively interested in electric power, and attentions are paid to natural energy, such as photovoltaic and wind power generation. Mega-solar is one of such targets that great efforts are made on. Verification tests carried out in Wakkanai city, Hokkaido [1] and Hokuto city, Yamanashi prefecture [2]. Quick and large penetration is expected.

However, in our country's small land area, since its installation has a limitation, they should be installed at appropriate locations in a rational and systematic manner. In installation of mega-solar, consideration on the safety in case of the natural disaster such as earthquakes is important. Its installation cost is greatly affected by the land cost of the location point. Therefore, it is necessary to consider various factors such as the amount of global solar radiation etc. in the mega-solar optimal installation. In this paper, Data Envelopment Analysis (DEA) is used to solve this problem [3]. This method is a technique of making relative evaluation on the productivity of Decision Making Unit (DMU), such as companies and public entities. Many works have been done [4]-[8] which applied this DEA method to various fields. [7] and [8] applied it to the problem of the location optimization of solar heat plants and wind plants. In these studies, the efficiency of each plant in Iran was evaluated.

Yokota et al. [9] applied this technique to the problem of the optimal allocation of photovoltaic power plant for the first time. But, only the input-oriented of CCR model in DEA was evaluated. So we perform ranking taking advantage of the characteristic of three models, BCC model [10], input-oriented model, and output-oriented model [11] in this paper. Moreover, we increase the number of the studied points (DMUs). Solutions are obtained on the mega-solar optimal allocation problem for Chubu District 81 points in Japan.

\section{DEA}

\section{A. CCR Model}

DEA is a method based on linear programming, and the method of relatively evaluating the efficiency of DMU, such as a set of firms etc. Usually, when considering the problem of efficiency, it can be expressed with (efficiency) $=$ (output) $/$ (input). In this formula, the efficiency becomes higher when input value is smaller, and output value is larger. However, since the influences which each input gives to each output may differ if the number of input or output increases, it may be unable to 
evaluate simply by the efficiency $\theta=$ (sum of output) / (sum of input). By DEA, the maximum of the efficiency of each DMU can be calculated by applying weight so that each parameter may become advantageous. Moreover, as a fundamental idea, accepting the property of each DMU and not limiting the optimal solution to one, it allows enhancing efficiency in the form that is best for each DMU. Say $\mathrm{DMU}_{j}$ is the target of our evaluation out of $n$ DMUs, the efficiency evaluation can be written to be

$$
\sum_{r=1}^{s} u_{r} y_{r j} / \sum_{i=1}^{m} v_{i} x_{i j}
$$

and what is necessary is just to solve the following fractional programming problem to know the most efficient status of operation.

$$
\begin{array}{ll}
\max & \sum_{r=1}^{s} u_{r} y_{r j} / \sum_{i=1}^{m} v_{i} x_{i j} \\
\text { s.t. } & \sum_{r=1}^{s} u_{r} y_{r k} / \sum_{i=1}^{m} v_{i} x_{i k} \leq 1 \quad(k=1,2, \ldots, n) \\
& u_{r} \geq 0 \quad(r=1,2, \ldots, s) \quad v_{i} \geq 0 \quad(i=1,2, \ldots, m)
\end{array}
$$

In the equation (1), $y, x, u$, and $v$ express output values, input values, output weights, and input weights of each parameter, respectively. And $s$ is the number of output data, $m$ is the number of input data. In addition, $k$ is the subscript given to all DMU which contain also except $\mathrm{DMU}_{j}$ made applicable to evaluation, and these inequality constraint need to be satisfied in all DMUs. If this objective function takes the value $1, j$ can be said to be the most efficient in that specific $u_{r}$ and $v_{i}$. Since this equation (1) is developed by Charnes, Cooper, and Rhodes, it is called CCR model.

For simplicity, the additional condition

$$
\sum_{i=1}^{m} v_{i} x_{i j}=1
$$

is considered in many cases, and this paper also follows this tradition. In this case, an optimization problem changes into the form of the following linear programming.

$$
\begin{aligned}
\max & \sum_{r=1}^{s} u_{r} y_{r j} \\
\text { s.t. } & \sum_{i=1}^{m} v_{i} x_{i j}=1 \\
& \sum_{r=1}^{s} u_{r} y_{r k} \leq \sum_{i=1}^{m} v_{i} x_{i k} \quad(k=1,2, \ldots, n) \\
& u_{r} \geq 0 \quad(r=1,2, \ldots, s) \quad v_{i} \geq 0 \quad(i=1,2, \ldots, m)
\end{aligned}
$$

The above equation (2) is called an input-oriented model. Changing this formula to the dual form, we can get equation (3).

$$
\begin{array}{ll}
\min & \theta_{j} \\
\text { s.t. } & \theta_{j} x_{i j}-\sum_{k=1}^{n} x_{i k} \lambda_{k} \geq 0 \quad(i=1,2, \ldots, m) \\
& y_{r j}-\sum_{k=1}^{n} y_{r k} \lambda_{k} \leq 0 \quad(r=1,2, \ldots, s) \\
& \lambda_{k} \geq 0 \quad(k=1,2, \cdots, n)
\end{array}
$$

As can be easily understood by this formula, this model minimizes the value of input as much as possible, maintaining output level. On the other hand, an outputoriented model can be expressed as follows [11].
Table I. - Example of parameter

\begin{tabular}{|c|c|c|c|c|c|}
\hline DMU & A & B & C & D & E \\
\hline Input & 3 & 4 & 2 & 1 & 3.5 \\
\hline Output & 3 & 2 & 4 & 1 & 5 \\
\hline
\end{tabular}

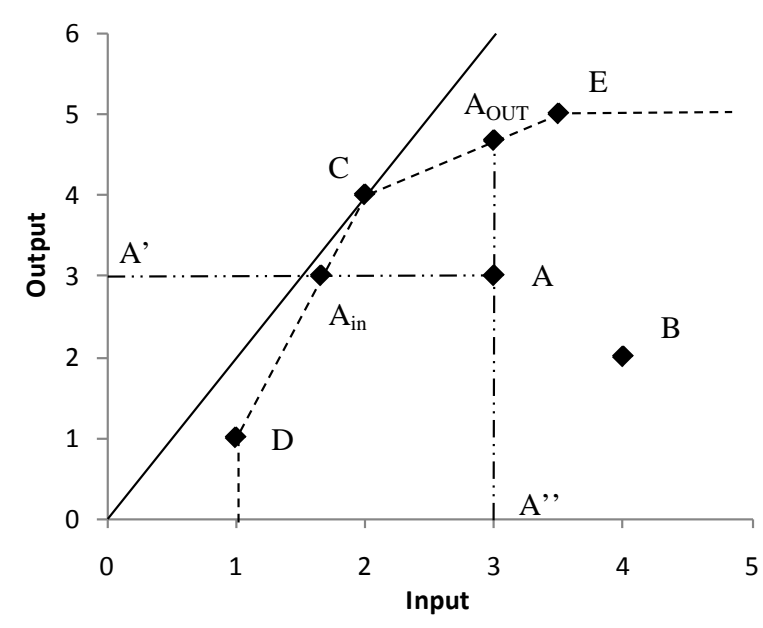

Fig. 1. Difference between CCR and BCC

$$
\begin{array}{ll}
\max & \phi_{j} \\
\text { s.t. } & x_{i j}-\sum_{k=1}^{n} x_{i k} \lambda_{k} \geq 0 \quad(i=1,2, \ldots, m) \\
& \phi_{j} y_{r j}-\sum_{k=1}^{n} y_{r k} \lambda_{k} \leq 0 \quad(r=1,2, \ldots, s) \\
& \lambda_{k} \geq 0 \quad(k=1,2, \cdots, n)
\end{array}
$$

This model maximizes the value of output as much as possible, maintaining input level. In CCR model, the input-oriented efficiency value is equivalent to the output-oriented efficiency value. $\left(\theta_{j}=1 / \varphi_{j}\right)$

\section{B. BCC Model}

The above CCR model is premised on the conditions of constant returns to scale. As opposed to this technique, Banker et al. [10] proposed BCC model, in which variable returns to scale. This type of system cannot be always run efficiently in large scale even if it is in highly efficient manners when small. Similarly, it cannot be always run efficiently in small scale even if it is in highly efficient manners when large. In BCC model, this variable return characteristic is modeled based on the real field activity. In the mathematical formulation, we should just add

$$
\sum_{k=1}^{n} \lambda_{k}=1(5)
$$

to the constraint condition of equations (3) and (4).

The difference between CCR model and BCC model is illustrated in Fig. 1, where each DMU shown in Table I is marked by a black rhombus. In CCR model, the solid line 
is called the efficient frontier, which implies the most efficient ratio between the input and the output. The dotted line (DCE) is the efficient frontier in BCC model. As shown here, DMUs evaluated as efficient by BCC model are not necessarily evaluated as efficient also by CCR model.

Moreover, in BCC model, the input-oriented efficiency differs from the output-oriented efficiency. In this example, the input-oriented efficiency is the length $A_{\text {in }} A^{\prime}$ divided by the length AA', whereas the output-oriented efficiency is the length $A_{\text {out }} A$ "' divided by the length AA', They are $5 / 9$ and $14 / 9$, respectively.

\section{SE-DEA Model}

In DEA application results, the efficiency values of many DMUs sometimes become 1 . This is no problem in mathematical sense, and is a theoretically sound consequence from the viewpoint of DEA for accepting the property of many DMUs. However, in the case of the present mega-solar point selection problem, this may lead to the problem that we cannot determine which candidate to choose. In order to narrow down the candidates out of result obtained by DEA, the following sensitivity analysis is applied.

$$
\begin{array}{ll}
\min & \theta_{j} \\
\text { s.t. } & \theta_{j} x_{i j}-\sum_{\substack{k=1 \\
k \neq j}}^{n} x_{i k} \lambda_{k} \geq 0 \quad(i=1,2, \ldots, m) \\
& \sum_{\substack{k=1 \\
k \neq j}}^{n} y_{r k} \lambda_{k} \geq y_{r j} \quad(r=1,2, \ldots s) \\
& \sum_{\substack{k=1 \\
k \neq j}}^{n} \lambda_{k}=1 \\
& \lambda_{k} \geq 0 \quad(k \neq j)
\end{array}
$$

The equation (6) is a sensitivity analysis by the inputoriented BCC model. The sensitivity analysis of the output-oriented BCC model should just add the equation (5) to the constraint condition of equation (4). $\quad(k \neq j)$ However, when this sensitivity analysis is conducted by BCC model, it sometimes becomes infeasible [12]. Some techniques are proposed for its improvement [13],[14]. In this study, we have tried to apply these techniques, but could not be solved. Therefore, the efficiency value of such DMUs are forced to be set to 1.0 .

Finally, the following equation is used when performing ranking of each place[14]. The wighting factors $w_{\theta}$ and $w_{\varphi}$ can take arbitrary value between 0 and 1 satisfying the conditon $w_{\theta}+w_{\varphi}=1$. They are set to 0.5 in this research.

$$
\begin{aligned}
& S_{I}=w_{\theta} \theta_{j}+w_{\phi} \frac{1}{\phi_{j}} \\
& S_{o}=w_{\theta} \frac{1}{\theta_{j}}+w_{\phi} \phi_{j}
\end{aligned}
$$

\section{Data}

The mega-solar installation candidates are shown in Fig. 2, which are 81 points in Mie prefecture, Shizuoka prefecture, Aichi prefecture, Gifu prefecture, and Nagano prefecture

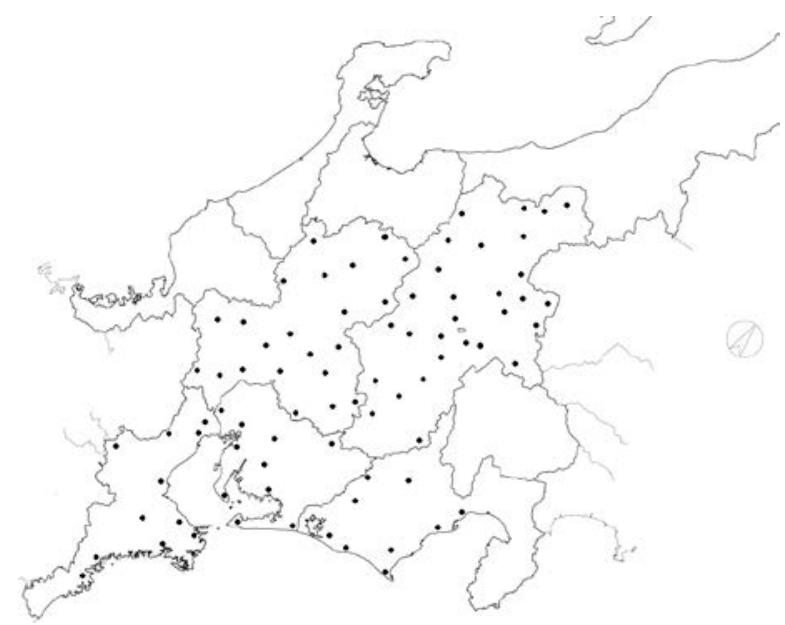

Fig. 2. Selected Location

of Japan (which are numbered below in random order). The amount of global solar radiation, population density, the land cost, the earthquake occurrence, and the transmission loss at each point are chosen as variables. Each data is explained below.

\section{A. Global Solar Radiation}

The amount of global solar radiation is important for choosing the area because it dominates the overall electric energy production. This data is recorded on METPV-3 of the New Energy and Industrial Technology Development Organization (NEDO), and is carried out based on the statistics in 1990 2003. Average value is newly computed from the amount of average year global solar radiation of these points. Since the larger amount of global solar radiation is favorable, it is considered as an output in DEA.

\section{B. Population Density}

Highly populated area is, in a sense, suitable for the mega-solar installation from the viewpoint of power flow distribution balance. Lager population density can be advantageous. Population density is obtained from the Ministry of Internal Affairs and Communications. This data is considered as an output in DEA from the above sense.

\section{Land Cost}

When installing mega-solar, the installation cost is one of the important parameters. Since this cost influenced by the land cost of each point greatly, the land cost in each place investigated. This data is obtained from the Ministry of Land, Infrastructure, Transport and Tourism. Since the lower land cost is advantageous, it is considered as an input in DEA.

\section{Earthquake Occurrence}

The mega-solar installation to the area where the 


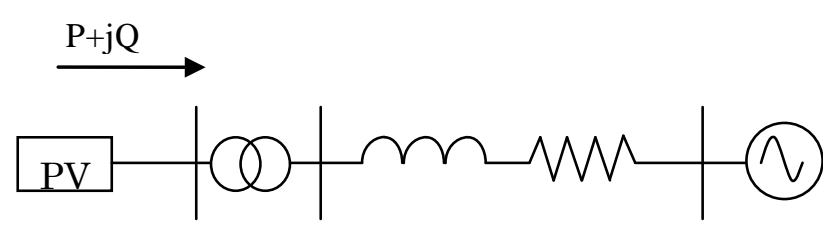

Fig. 3. Mega-solar System

Table II. - Line Constant

\begin{tabular}{|l|l|}
\hline & $\operatorname{ACSR}\left(160 \mathrm{~mm}^{2}\right)$ \\
\hline $\mathrm{R}[\Omega / \mathrm{km}]$ & 0.182 \\
\hline$\omega \mathrm{L}[\Omega / \mathrm{km}]$ & 0.502296 \\
\hline
\end{tabular}

earthquake frequently occurs is not desirable, not only in the sense of safety but also in the sense of maintenance. The accumulated number of the earthquake occurrence (NE) and the data of the observation start year (SY) are obtained from the Meteorological Agency. The degree of earthquake frequency, which is NE divided by (2011-SY) is used to evaluate the earthquake occurrence. From the above viewpoint, this data is considered as an input in DEA.

\section{E. Transmission Loss}

We have to connect the mega-solar station to the grid, in order to supply electric power from it. Long distance transmission from mega-solar station gives rise to loss. Then, it assumed to the nearest substation assuming connecttion, the expected transmission loss is calculated. Since the lower transmission loss is better, this data is considered as an input in DEA.

To calculate this data, the distance from each site to its nearest substation is geographically measured. Since the main mega-solar installation area needs over $30000\left[\mathrm{~m}^{2}\right]$ in Japan, required land area is set to $40000\left[\mathrm{~m}^{2}\right]$.

To calculate the transmission loss, the mega-solar is assumed to be connected as shown in Fig. 3. The transmission loss is calculated on the basis of the maximum power generation, the day of the maximum solar radiation. The output from PV panel is set to $2.7[\mathrm{MW}]$ by $100[\mathrm{~kW}] \times 27$, and the loss of the panel is set to 0.155 [15]. It is assumed that the transformer capacity is $3000[\mathrm{~kW}]$ and a reactance value is 5.5[\%]. Rated (norminal) voltage is $33[\mathrm{kV}]$ and Frequency is $60[\mathrm{~Hz}]$. A Line Constant is indicated in Table II [16]. The transmission loss at each place is computed from the above conditions, and the value is applied to DEA.

Table III shows the above five data, where all the numerical value shows a relative value on the basis of a maximum value. LP Solve is used in our calculations.

\begin{tabular}{|c|c|c|c|c|c|}
\hline Point & $\begin{array}{l}\text { Land } \\
\text { Cost } \\
\text { (p.u.) }\end{array}$ & $\begin{array}{c}\text { Earth- } \\
\text { quake } \\
\text { Occur } \\
\text {-rence } \\
\text { (p.u.) }\end{array}$ & $\begin{array}{l}\text { Loss } \\
\text { (p.u.) }\end{array}$ & $\begin{array}{c}\text { Global } \\
\text { Solar } \\
\text { Radia- } \\
\text { tion } \\
\text { (p.u.) }\end{array}$ & $\begin{array}{c}\text { Popu- } \\
\text { lation } \\
\text { Densi- } \\
\text { ty } \\
\text { (p.u.) }\end{array}$ \\
\hline & $v_{1}$ & $v_{2}$ & $v_{3}$ & $u_{1}$ & $u_{2}$ \\
\hline $\mathrm{DMU}_{1}$ & 0.362 & 0.113 & 0.281 & 0.840 & 0.149 \\
\hline $\mathrm{DMU}_{2}$ & 0.345 & 0.140 & 0.184 & 0.891 & 0.218 \\
\hline $\mathrm{DMU}_{3}$ & 0.203 & 0.062 & 0.079 & 0.825 & 0.038 \\
\hline $\mathrm{DMU}_{4}$ & 0.166 & 0.118 & 0.318 & 0.855 & 0.026 \\
\hline $\mathrm{DMU}_{5}$ & 0.252 & 0.127 & 0.145 & 0.916 & 0.238 \\
\hline $\mathrm{DMU}_{6}$ & 0.254 & 0.083 & 0.188 & 0.808 & 0.039 \\
\hline $\mathrm{DMU}_{7}$ & 0.280 & 0.059 & 0.126 & 0.855 & 0.080 \\
\hline $\mathrm{DMU}_{8}$ & 0.222 & 0.023 & 0.027 & 0.833 & 0.031 \\
\hline $\mathrm{DMU}_{9}$ & 0.097 & 0.027 & 0.117 & 0.832 & 0.010 \\
\hline $\mathrm{DMU}_{10}$ & 0.180 & 0.113 & 0.281 & 0.839 & 0.013 \\
\hline $\mathrm{DMU}_{11}$ & 0.188 & 0.079 & 0.165 & 0.884 & 0.016 \\
\hline $\mathrm{DMU}_{12}$ & 0.667 & 0.147 & 0.226 & 0.827 & 0.148 \\
\hline $\mathrm{DMU}_{13}$ & 0.879 & 0.189 & 0.257 & 0.942 & 0.420 \\
\hline $\mathrm{DMU}_{14}$ & 0.110 & 0.082 & 0.211 & 0.811 & 0.002 \\
\hline $\mathrm{DMU}_{15}$ & 0.254 & 0.186 & 0.229 & 0.849 & 0.074 \\
\hline $\mathrm{DMU}_{16}$ & 0.141 & 0.085 & 0.111 & 0.974 & 0.078 \\
\hline $\mathrm{DMU}_{17}$ & 0.356 & 0.034 & 0.065 & 0.888 & 0.153 \\
\hline $\mathrm{DMU}_{18}$ & 0.770 & 0.112 & 0.064 & 0.942 & 0.345 \\
\hline $\mathrm{DMU}_{19}$ & 0.326 & 0.073 & 0.066 & 0.809 & 0.017 \\
\hline $\mathrm{DMU}_{20}$ & 0.096 & 0.110 & 0.099 & 0.804 & 0.004 \\
\hline $\mathrm{DMU}_{21}$ & 0.466 & 0.159 & 0.086 & 0.855 & 0.145 \\
\hline $\mathrm{DMU}_{22}$ & 1 & 0.233 & 0.097 & 0.922 & 1 \\
\hline $\mathrm{DMU}_{23}$ & 0.582 & 0.080 & 0.177 & 0.859 & 0.354 \\
\hline $\mathrm{DMU}_{24}$ & 0.615 & 0.228 & 0.074 & 0.841 & 0.186 \\
\hline $\mathrm{DMU}_{25}$ & 0.119 & 0.056 & 0.158 & 0.773 & 0.004 \\
\hline $\mathrm{DMU}_{26}$ & 0.615 & 0.186 & 0.279 & 0.839 & 0.230 \\
\hline $\mathrm{DMU}_{27}$ & 0.195 & 0.118 & 0.140 & 0.875 & 0.084 \\
\hline $\mathrm{DMU}_{28}$ & 0.529 & 0.075 & 0.098 & 0.860 & 0.213 \\
\hline $\mathrm{DMU}_{29}$ & 0.579 & 0.191 & 0.268 & 0.855 & 0.210 \\
\hline $\mathrm{DMU}_{30}$ & 0.233 & 0.086 & 0.124 & 0.942 & 0.051 \\
\hline $\mathrm{DMU}_{31}$ & 0.039 & 0.120 & 0.131 & 0.769 & 0.000 \\
\hline $\mathrm{DMU}_{32}$ & 0.262 & 0.123 & 0.137 & 0.812 & 0.005 \\
\hline $\mathrm{DMU}_{33}$ & 0.060 & 0.188 & 0.398 & 0.786 & 0.001 \\
\hline $\mathrm{DMU}_{34}$ & 0.457 & 0.085 & 0.520 & 0.838 & 0.069 \\
\hline $\mathrm{DMU}_{35}$ & 0.042 & 0.062 & 0.068 & 0.760 & 0.000 \\
\hline $\mathrm{DMU}_{36}$ & 0.030 & 0.076 & 0.580 & 0.767 & 0.001 \\
\hline $\mathrm{DMU}_{37}$ & 0.178 & 0.056 & 0.425 & 0.752 & 0.009 \\
\hline $\mathrm{DMU}_{38}$ & 0.397 & 0.126 & 0.124 & 0.801 & 0.009 \\
\hline $\mathrm{DMU}_{39}$ & 0.166 & 0.104 & 0.239 & 0.788 & 0.011 \\
\hline $\mathrm{DMU}_{40}$ & 0.350 & 0.131 & 0.208 & 0.784 & 0.010 \\
\hline $\mathrm{DMU}_{41}$ & 0.143 & 0.092 & 0.156 & 0.780 & 0.006 \\
\hline $\mathrm{DMU}_{42}$ & 0.097 & 0.220 & 0.113 & 0.785 & 0.018 \\
\hline $\mathrm{DMU}_{43}$ & 0.108 & 0.042 & 1 & 0.815 & 0.006 \\
\hline $\mathrm{DMU}_{44}$ & 0.184 & 0.064 & 0.129 & 0.811 & 0.029 \\
\hline $\mathrm{DMU}_{45}$ & 0.203 & 0.122 & 0.430 & 0.713 & 0.013 \\
\hline $\mathrm{DMU}_{46}$ & 0.104 & 0.103 & 0.076 & 0.815 & 0.016 \\
\hline $\mathrm{DMU}_{47}$ & 0.185 & 0.164 & 0.149 & 0.823 & 0.102 \\
\hline $\mathrm{DMU}_{48}$ & 0.238 & 0.132 & 0.116 & 0.819 & 0.196 \\
\hline $\mathrm{DMU}_{49}$ & 0.091 & 0.126 & 0.285 & 0.812 & 0.004 \\
\hline $\mathrm{DMU}_{50}$ & 0.474 & 0.180 & 0.132 & 0.896 & 0.302 \\
\hline $\mathrm{DMU}_{51}$ & 0.369 & 0.150 & 0.083 & 0.838 & 0.279 \\
\hline $\mathrm{DMU}_{52}$ & 0.155 & 0.100 & 0.101 & 0.788 & 0.025 \\
\hline $\mathrm{DMU}_{53}$ & 0.222 & 0.130 & 0.542 & 0.807 & 0.010 \\
\hline $\mathrm{DMU}_{54}$ & 0.151 & 0.257 & 0.170 & 0.810 & 0.018 \\
\hline $\mathrm{DMU}_{55}$ & 0.115 & 0.264 & 0.087 & 0.779 & 0.009 \\
\hline $\mathrm{DMU}_{56}$ & 0.083 & 0.122 & 0.088 & 0.789 & 0.007 \\
\hline
\end{tabular}




\begin{tabular}{|l|l|l|l|l|l|}
\hline DMU $_{57}$ & 0.483 & 0.843 & 0.294 & 0.898 & 0.076 \\
\hline DMU $_{58}$ & 0.120 & 0.168 & 0.321 & 0.804 & 0.011 \\
\hline DMU $_{59}$ & 0.100 & 0.104 & 0.258 & 0.802 & 0.009 \\
\hline DMU $_{60}$ & 0.157 & 0.029 & 0.255 & 0.861 & 0.009 \\
\hline DMU $_{61}$ & 0.306 & 0.149 & 0.266 & 0.898 & 0.103 \\
\hline DMU $_{62}$ & 0.191 & 0.055 & 0.267 & 0.863 & 0.041 \\
\hline DMU $_{63}$ & 0.555 & 0.170 & 0.134 & 0.892 & 0.016 \\
\hline DMU $_{64}$ & 0.210 & 0.145 & 0.126 & 0.819 & 0.042 \\
\hline DMU $_{65}$ & 0.479 & 0.128 & 0.125 & 1 & 0.115 \\
\hline DMU $_{66}$ & 0.100 & 0.255 & 0.244 & 0.863 & 0.018 \\
\hline DMU $_{67}$ & 0.226 & 0.279 & 0.318 & 0.865 & 0.034 \\
\hline DMU $_{68}$ & 0.016 & 0.055 & 0.411 & 0.799 & 0.001 \\
\hline DMU $_{69}$ & 0.030 & 0.587 & 0.488 & 0.819 & 0.001 \\
\hline DMU $_{70}$ & 0.287 & 0.154 & 0.131 & 0.831 & 0.003 \\
\hline DMU $_{71}$ & 0.347 & 1 & 0.110 & 0.927 & 0.071 \\
\hline DMU $_{72}$ & 0.186 & 0.130 & 0.229 & 0.849 & 0.019 \\
\hline DMU $_{73}$ & 0.113 & 0.176 & 0.672 & 0.870 & 0.025 \\
\hline DMU $_{74}$ & 0.063 & 0.625 & 0.233 & 0.824 & 0.003 \\
\hline DMU $_{75}$ & 0.205 & 0.140 & 0.429 & 0.864 & 0.044 \\
\hline DMU $_{76}$ & 0.167 & 0.280 & 0.095 & 0.847 & 0.007 \\
\hline DMU $_{77}$ & 0.140 & 0.198 & 0.313 & 0.864 & 0.017 \\
\hline DMU $_{78}$ & 0.087 & 0.190 & 0.328 & 0.804 & 0.003 \\
\hline DMU $_{79}$ & 0.276 & 0.198 & 0.125 & 0.918 & 0.047 \\
\hline DMU $_{80}$ & 0.030 & 0.113 & 0.313 & 0.851 & 0.001 \\
\hline DMU $_{81}$ & 0.015 & 0.089 & 0.108 & 0.777 & 0.007 \\
\hline & & & & & \\
\hline
\end{tabular}

\section{Results}

Table IV shows DMUs from which the efficiency value is set to 1 in BCC model. The data of Table III is applied by the input-oriented CCR model and the input-oriented and the output-oriented BCC models, and the result of the sensitivity analysis is also shown in Table IV.

The point where the data of the input is small showed the more efficient value, comparing the input-oriented model result with data. On the contrary, the point where the data of the output is large showed the more efficient value, comparing the output-oriented model result with data.

In the input-oriented model, calculation becomes infeasible at two places, whereas in the output-oriented model infeasible at five places. Calculation become infeasible in seven cases in total, because this paper treats larger numbers of outputs and DMUs than those in [14]. Next, the efficiency value of the point where calculation becomes infeasible is set to 1 , the efficiency values of the input-oriented and the output-oriented are integrated using the equation (7), and the values of $S_{I}$ and $S_{O}$ are calculated. Large $S_{I}$ and small $S_{O}$ imply high efficiency. The top three candidates are $\mathrm{DMU}_{16}, \mathrm{DMU}_{17}$, and $\mathrm{DMU}_{22}$. If we focus attention on the value of $S_{I}$, ranking will be $\mathrm{DMU}_{22}$, $\mathrm{DMU}_{16}, \mathrm{DMU}_{17}$. If we focus attention on the value of $S_{O}$, ranking will be $\mathrm{DMU}_{17}, \mathrm{DMU}_{16}, \mathrm{DMU}_{22}$. In the feature of these three DMUs, as compared with data, $\mathrm{DMU}_{16}$ is second-largest in the amount of global solar radiation and inputs have comparatively small values. Although $\mathrm{DMU}_{17}$ has fourth-smallest earthquake occurrence and the loss is third-smallest, the value of the land cost is large. $\mathrm{DMU}_{22}$ is the point where the land cost is the highest, while population density is the largest. In CCR model, $\mathrm{DMU}_{16}$ is

Table IV. - Results

\begin{tabular}{|c|c|c|c|c|c|}
\hline Point & CCR & $\begin{array}{c}\text { Input- } \\
\text { oriented }\end{array}$ & $\begin{array}{c}\text { Output- } \\
\text { oriented }\end{array}$ & $\mathrm{S}_{\mathrm{I}}$ & $\mathrm{S}_{\mathrm{O}}$ \\
\hline $\mathrm{DMU}_{5}$ & 1.0008 & 1.093607 & 0.9524989 & 1.07174 & 0.93345 \\
\hline $\mathrm{DMU}_{8}$ & 2.22840 & 2.417120 & infeasible & 1.70856 & 0.70686 \\
\hline $\mathrm{DMU}_{9}$ & 1.37982 & 1.394187 & infeasible & 1.19709 & 0.85863 \\
\hline $\mathrm{DMU}_{16}$ & 0.96779 & 2.609837 & 0.8762254 & 1.87555 & 0.62970 \\
\hline $\mathrm{DMU}_{17}$ & 1.36123 & 1.841881 & 0.5842974 & 1.77667 & 0.56361 \\
\hline $\mathrm{DMU}_{18}$ & 0.82174 & 1.505003 & 0.9419112 & 1.28334 & 0.80318 \\
\hline $\mathrm{DMU}_{22}$ & 2.09198 & infeasible & 0.3581903 & 1.89591 & 0.67910 \\
\hline $\mathrm{DMU}_{23}$ & 0.99662 & 1.004207 & 0.9959145 & 1.00416 & 0.99586 \\
\hline $\mathrm{DMU}_{35}$ & 1.28641 & 1.334918 & infeasible & 1.16746 & 0.87456 \\
\hline $\mathrm{DMU}_{60}$ & 0.93173 & 1.168498 & 0.9816134 & 1.09362 & 0.91871 \\
\hline $\mathrm{DMU}_{65}$ & 0.52852 & infeasible & 0.9722234 & 1.01429 & 0.98611 \\
\hline $\mathrm{DMU}_{68}$ & 1.52494 & 1.624796 & infeasible & 1.31240 & 0.80773 \\
\hline $\mathrm{DMU}_{80}$ & 0.70984 & 1.771562 & 0.9564656 & 1.40854 & 0.76047 \\
\hline $\mathrm{DMU}_{81}$ & 2.24608 & 2.264061 & infeasible & 1.63203 & 0.72084 \\
\hline
\end{tabular}

not efficient, but it is turned out to be efficient evaluating by BCC model.

\section{Conclusion}

In this paper, DEA is applied to the problem of the megasolar optimal allocation for Chubu District 81 points in japan, and the efficiency value is measured. By evaluating both models of input-oriented and outputoriented, we avoid one sided evaluation. Moreover, it is shown that the candidate which is evaluated as not efficient by CCR model can become efficient in the case of BCC model.

In our future studies, various types of data will be treated. Furthermore, we plan to improve the feasibility of the proposed method.

\section{References}

[1] M. Akatsuka, R. Hara, H. Kita, T. Ito, Y. Ueda, Y. Saito, "Estimation of battery for suppression of a PV power plant output fluctuation,” IEEE PVSC , 2010, pp. 000540-000543

[2] H. Konishi, T. Iwato, M. Kudou, "Development of Largescale Power Conditioning System in Hokuto Mega-solar Project," IPEC, 2010, pp. 1975-1979

[3] A. Charnes, W.W. Cooper, E. Rhodes, "Measuring efficiency of decision making units," European Journal of Operational Research, Vol.2, 1978, pp.429-444

[4] H. M. Khodr, D. Feijoo, E. Perez, I. J. Zerpa, P. M. De Oliveira-De Jesus, J. M. Yusta, "Efficiency Control of the Electrical Distribution Utilities Using Data Envelopment Analysis,” IEEE/PES TDC, 2006, pp. 1-6

[5] Chen-Fu Chien, Wen-Chih Chen, Feng-Yu Lo, Yi-Chiech Lin, "A Case Study to Evaluate the Productivity Changes of the Thermal Power Plants of the Taiwan Power Company,” IEEE Transactions on Energy Conversion, vol. 22, 2007, pp. 680-688 [6] A.Azadeh, S.F. Ghaderi, M.R. Nasrollahi, "Energy Efficiency Modeling and Estimation in Petroleum Refining Industry - A Comparison Using Physical Data” (ICREPQ'8), 2008, http://www.icrepq.com.

[7] A. Azadeh, S.F. Ghaderi, A. Maghsoudi, "Location optimization of solar plants by an integrated hierarchical DEA PCA approach,” Energy Policy ,vol.36,2008, pp.3993-4004

[8] A. Azadeh, S.F. Ghaderi, M.R. Nasrollahi, "Location optimization of wind plants in Iran by an integrated hierarchical 
Data Envelopment Analysis,” Renewable Energy, vol.36, 2011, pp.1621-1631

[9] S. Yokota, T. Kumano, "Mega-solar Optimal Allocation using Data Envelopment Analysis" IEEJ Trans. PE, vol.131, No.10, 2011, pp.819-825

[10] R. D. Banker, A. Charnes, W. W. Cooper, "Some Models for Estimating Technical and Scale Inefficiencies in Data Envelopment Analysis” Management Science, vol. 30, 1984, pp.1078-1092

[11] L. M. Seiford, R. M. Thrall, "Recent developments in DEA: The mathematical programming approach to frontier analysis" Journal of Econometrics 46, 1990, pp.7-38

[12] L. M. Seiford, J. Zhu, "Infeasibility of super-efficiency data envelopment analysis models" INFOR, Vol.37, 1999, pp.174-187. [13] Y. Chen, "Measuring super-efficiency in DEA in the presence of infeasibility" European Journal of Operational Research, Vol.161, 2005, pp.545-551.

[14] Y. Chen, "Ranking efficient units in DEA" Management Science, Vol.32, 2004, pp.213-219.

[15] The New Energy and Industrial Technology Development Organization "Investigation about photovoltaic generation system stabilization for large-scale power supplies” 2006-3 (in Japanese) [16] K. Aratame "The foundation of power system technical calculation” 1980 (in Japanese) 